\title{
Differential photo-calorimetry of photopolymerizable ceramic suspensions
}

\author{
G. A. BRADY, J. W. HALLORAN \\ Materials Science and Engineering Department, The University of Michigan, Ann Arbor, \\ MI 48109-2136, USA \\ E-mail: John-Halloran@mse.engin.umich.edu
}

\begin{abstract}
Suspensions of alumina powders in low-viscosity acrylate monomers were produced and their curing behaviour characterized. Although these suspensions contain 50 vol $\% \mathrm{Al}_{2} \mathrm{O}_{3}$ particles, the viscosity is between 200 and $300 \mathrm{mPas}$. These suspensions were rendered ultraviolet-curable by the addition of photoinitiators sensitive to ultraviolet radiation. Photopolymerization kinetics were characterized via differential photo-calorimetry. Photopolymerization rates and monomer conversions were unaffected by the presence of the alumina filler. Increasing the average functionality of the monomer mixture tended to increase slightly the photopolymerization rate and decrease the final conversion. Higher concentrations of photoinitiator increased both the rate of photopholymerization and the final conversion. The presence of oxygen was shown severely to restrict polymerization in these filled systems as well. (c) 1998 Kluwer Academic Publishers
\end{abstract}

\section{Introduction}

Photopolymerization of concentrated ceramic suspensions is finding application in a variety of fabrication techniques. It is useful for tape casting [1-4] where photocuring of a monomer-containing suspension medium solidifies the tape as an alternative to solvent evaporation. Photocured suspensions can also be used to prepare ceramic replicas of photolithographically patterned silicon [5]. Recently, photocurable suspensions have been used for solid free-form fabrication of ceramics by stereolithography [6-9] using ultraviolet (UV) laser drawing and by mask exposure using visible light [10].

The process of photopolymerization is well understood for clear resins [11-14] and pigmented resins having small loadings of oxide powders [15]. The present work studied very concentrated suspensions of interest for ceramics. These systems are based on freeradial polymerization of acrylates, but contain a high fraction of particles which are strong scatterers $[9,16]$. We adopt the standard technique of photocalorimetry [11] to measure the rate and extent of polymerization.

The scheme employed to produce these curable ceramic resins consists of suspending ceramic particles in a UV-curable liquid monomer mixture. These suspensions must contain high solids content ( $\sim 50 \mathrm{vol} \%$ ), yet remain fluid. Further, upon exposure to UV radiation, the suspension should polymerize into a stiff gel. The newly formed polymer acts as a binder for the ceramic particles. After forming this ceramic "green" body, the binder is pyrolysed, and subsequent heating sinters the ceramic particles into a strong, dense ceramic body [17].
This work focuses on the characterization of the photopolymerization of these ceramic suspensions, or "ceramic resins" via photocalorimetry. This method allows the polymerization reaction to be followed in real-time. The photocurable monomer mixtures used in this study are composed of mono- and di-functional acrylate monomers. The polymerization kinetics of several mixtures of these monomers are compared to examine the effect of average functionality. These same monomer mixtures are then filled with $50 \mathrm{vol} \%$ $\mathrm{Al}_{2} \mathrm{O}_{3}$ to form UV curable ceramic suspensions and the photopolymerization behaviour is similarly analysed. Further, the effect of photoinitiator concentration in the ceramic resins on photopolymerization kinetics is examined. Finally, because free-radical polymerization of acrylate monomers are inhibited by the presence of oxygen, the effect of atmosphere is examined.

\section{Experimental procedure}

Three separate monomer mixtures were prepared from 1,6-hexanediol diacrylate, HDDA (Photomer 4017, Henkel Corp., Kankakee, IN), and 2phenoxyethyl acrylate, POEA (Sartomer 339, Sartomer Co., West Chester, PA), in the following amounts: $100 \mathrm{wt} \%$ HDDA, $50 \mathrm{wt} \%$ HDDA, and $10 \mathrm{wt} \%$ HDDA. These monomers and their structure formulas are shown in Fig. 1. Unless otherwise specified, 1-hydroxy cyclohexyl phenyl ketone (Irgacure 184, Ciba Specialty Chemicals, Tarrytown, NY) was added as a photoinitiator at a concentration of $0.5 \mathrm{wt} \%$ with respect to monomer. All materials were used as received from the supplier. 
<smiles>C=CC(=O)OCCCCCCOC(=O)C=C</smiles>

HDDA (1,6-hexanediol diacrylate)<smiles>C=CC(=O)OCCOc1ccccc1</smiles>

POEA (2-Phenoxyethyl acrylate)

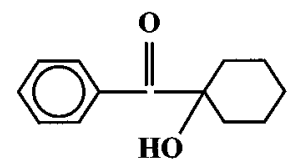

HCPK (1-hydroxy cyclohexyl phenyl ketone)

Figure 1 The monomers and photoinitiator used in this study.

TABLE I List of resin compositions (wt \%)

\begin{tabular}{lrrlrl}
\hline Resin & HDDA & POEA & PI & $\mathrm{Al}_{2} \mathrm{O}_{3}$ & Disp. \\
\hline Neat 100 & \multicolumn{1}{c}{99.5} & 0.00 & 0.50 & 0.00 & 0.00 \\
Neat 50 & 49.75 & 49.75 & 0.50 & 0.00 & 0.00 \\
Neat 10 & 9.95 & 89.55 & 0.50 & 0.00 & 0.00 \\
Filled 100 & 20.14 & 0.00 & 0.10 & 78.19 & 1.56 \\
Filled 50 & 10.40 & 10.40 & 0.10 & 77.54 & 1.55 \\
Filled 10 & 2.13 & 19.16 & 0.11 & 77.06 & 1.54 \\
Filled 100-1.0 & 20.12 & 0.0 & 0.20 & 78.11 & 1.56 \\
Filled 100-2.0 & 20.08 & 0.0 & 0.40 & 77.96 & 1.56 \\
Filled 100-3.0 & 20.04 & 0.0 & 0.60 & 77.80 & 1.56 \\
\hline
\end{tabular}

Ceramic suspensions were prepared by mixing $\mathrm{Al}_{2} \mathrm{O}_{3}$ powder (RC-HP DBM, Malakoff Industries, Inc., Malakoff, TX; $0.3 \mu \mathrm{m}$ average size) with the liquid monomer mixtures in a milling jar containing $1 / 4$ in. $(\sim 6.25 \mathrm{~mm})$ cylindrical alumina milling media. Stable colloidal dispersions were obtained by incremental additions of $\mathrm{Al}_{2} \mathrm{O}_{3}$ powder and $2 \mathrm{wt} \%$ dispersant (Emcol CC-55, Witco Corp., Organics Division, New York, NY) followed by high-shear mixing for 5 min to deagglomerate and homogenize the mixture. At a solids loading of $50 \mathrm{vol} \%$, the mixture was ball-milled for $24 \mathrm{~h}$. Hydroxy cyclohexyl phenyl ketone was added to the $50 \mathrm{vol} \%$ suspension and the final mixture was ball-milled again for $2 \mathrm{~h}$. Separate suspensions were made with $100 \mathrm{wt} \%$ HDDA monomer which contained various amounts of photoinitiator. Table I lists each formulation and its general composition.

Calorimetric measurements were performed in a Perkin-Elmer DSC-7 with a customized head as shown in Fig. 2. A medium pressure, mercury-vapour UV source (Pen-Ray lamp, Model 11SC-1L, UVP Inc., Upland, CA) was placed in the head for irradiation. The intensity in this configuration was measured by a radiometer (Model IL390B, International Light, Inc., Newburyport, MA) and was found to be $7.3 \mathrm{~mW}$ $\mathrm{cm}^{-2}$. Each sample weighed between 1 and $10 \mathrm{mg}$ and

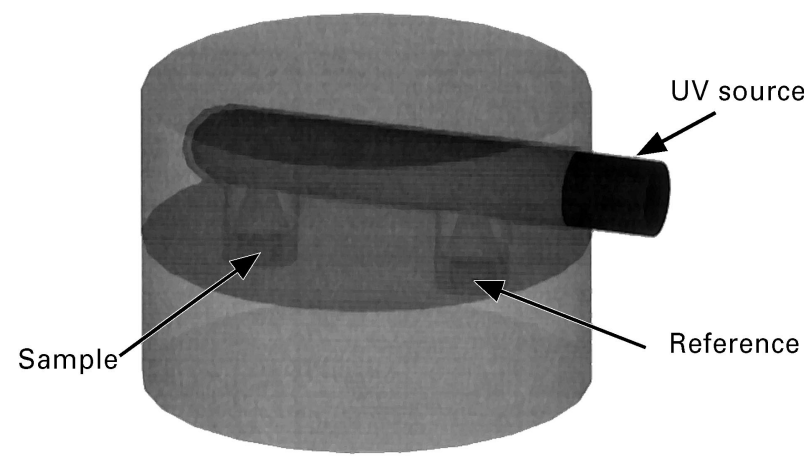

Figure 2 Schematic drawing of differential photo calorimetry setup.

was placed in open aluminium sample pans. Each sample was held in isothermal conditions at $40{ }^{\circ} \mathrm{C}$ in flowing nitrogen for $5 \mathrm{~min}$ prior to irradiation to purge the atmosphere of oxygen and equilibrate the temperature. For experiments in air, the nitrogen source tank was replaced with a dry compressed air tank. The photopolymerization reaction was carried out for $5 \mathrm{~min}$ (to a dose of $\sim 2100 \mathrm{~mJ} \mathrm{~cm}^{-2}$ ). The data reported for each composition is an average of three separate photopolymerizations.

\section{Results}

The free-radical photopolymerization reaction is exothermic and the kinetics are monitored by measuring the heat flow from the sample during irradiation. All heat generation during polymerization is assumed to be attributed to the reaction of the acrylate double bonds present in the monomers. This was confirmed by producing baselines from irradiation of an empty sample pan and a pan with alumina powder, both of which yielded insignificant changes in heat flow. The reaction rate is calculated from the reaction enthalpy flow by the equation

$$
R_{\mathrm{p}}=\frac{\mathrm{d} H}{\mathrm{~d} t} /\left(n \Delta H_{0} m\right)
$$

where $\mathrm{d} H / \mathrm{d} t$ is the reaction enthalpy flow measured by the DSC unit, $n$ is the number of $\mathrm{C}=\mathrm{C}$ bonds per monomer $\left(n=2\right.$ for HDDA, $n=1$ for POEA), $\Delta H_{0}$ is the standard enthalpy of reaction for the acrylate double bond $\left(\Delta H_{0}=86.2 \mathrm{~kJ} \mathrm{~mol}^{-1}[18]\right.$ for these calculations), and $m$ is the moles of acrylate monomer in the sample. These rate calculations are normalized to represent the number fraction of $\mathrm{C}=\mathrm{C}$ bonds reacting in the sample per unit dose (i.e. time, because the intensity is a constant $7.3 \mathrm{~mW} \mathrm{~cm}{ }^{-2}$ ).

The photopolymerization exotherms for the three neat (i.e. no ceramic) monomer mixtures are shown in Fig. 4. Although each reaction was carried out to about $2100 \mathrm{~mJ} \mathrm{~cm}^{-2}$ (5 min), data are shown only to $500 \mathrm{~mJ} \mathrm{~cm}^{-2}$ because the amount of reaction occurring after this point was insignificant. The monomer conversion was calculated from the exothermic heat flow over the exposure time according to the equation

$$
\alpha(t)=\frac{\Delta H(t)}{n \Delta H_{0} m}
$$




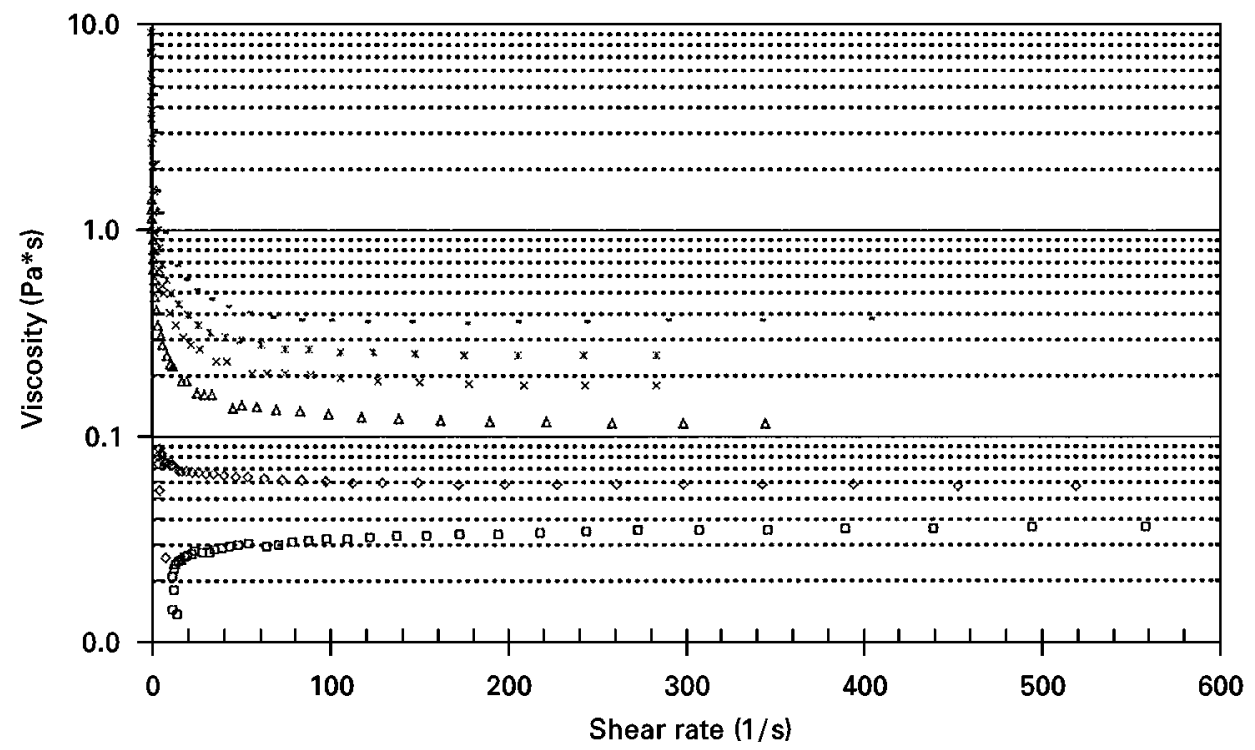

Figure 3 Viscosity versus shear rate for $\mathrm{Al}_{2} \mathrm{O}_{3} \mathrm{HDDA}$ at various solids loading $(\square) 20 \%,(\diamond) 30 \%(\triangle) 40 \% \mathrm{~m}(\times) 45 \% \mathrm{~m}(*) 47.5 \%,(-) 50 \%$

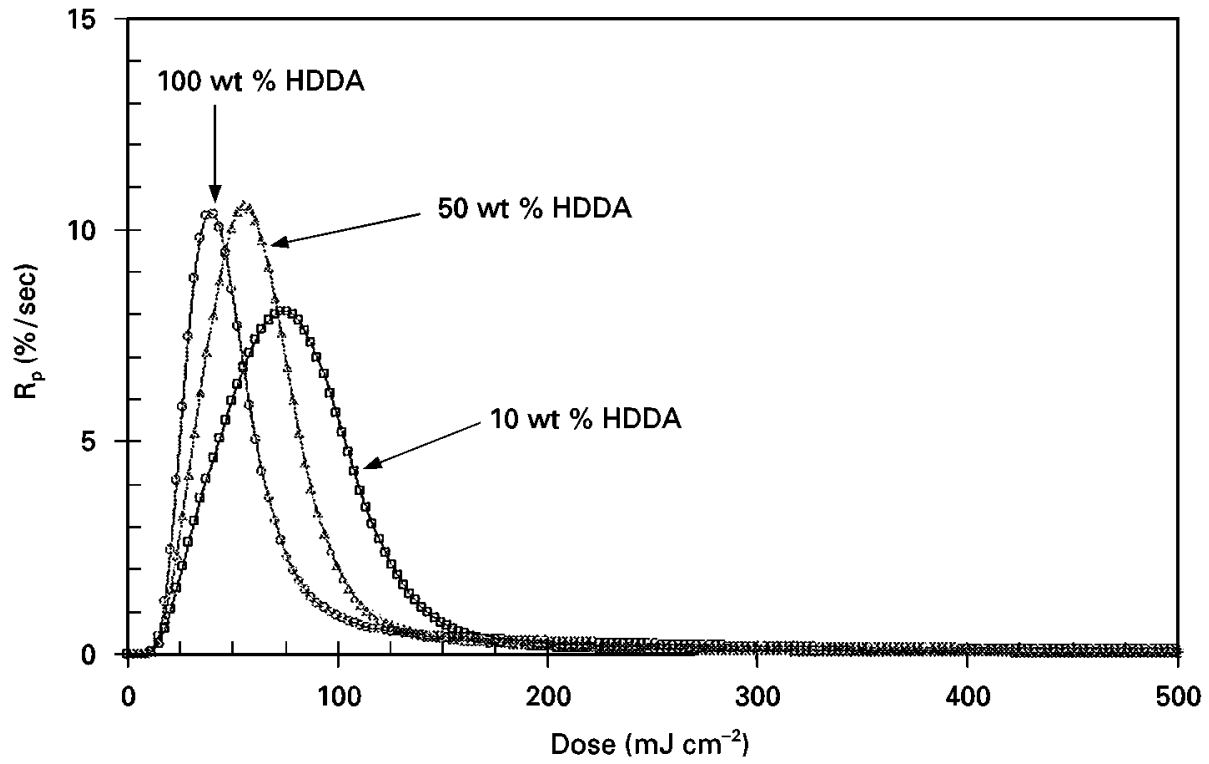

Figure 4 Rate of polymerization versus dose for neat monomer mixtures.

where $\Delta H(t)$ is the total heat evolved at time $t$. Fig. 5 shows the progression of polymerization expressed as conversion versus dose for the neat monomer mixtures. At $100 \%$ HDDA, the conversion plateaus at a significantly lower value than the other mixtures of lower average functionality. Maximum reaction rates, dose at $R_{\mathrm{p}(\max )}$, final conversions and conversions at $R_{\mathrm{p}(\max )}$ are also listed in Table II for those monomer mixtures.

As the ceramic particles are added to the liquid monomer mixtures, the viscosity of the mixture increases from about $35 \mathrm{mPa}$ at $10 \mathrm{vol} \%$ to $200 \mathrm{mPas}$ at $50 \mathrm{vol} \%$ ceramic. As shown in Fig. 3, the suspension shows some structure which is broken down at the low shear rates to yield a nearly Newtonian fluid at intermediate shear rates. The low viscosity and long-term stability from settling of these suspensions indicate excellent colloidal dispersion. A more complete rheological characterization of these suspensions as well as in situ rheological changes during photopolymerization, are given elsewhere [7].

The photopolymerization rate versus dose for monomer mixtures filled to $50 \mathrm{vol} \% \mathrm{Al}_{2} \mathrm{O}_{3}$ is shown in Fig. 6. The exotherm data are very similar to the neat monomers in that autoacceleration and decceleration are similarly indicated. The monomer conversion of the ceramic resins is shown in Fig. 7. The effect of the monomer composition is also similar to the neat mixtures in that the $100 \mathrm{wt} \%$ HDDA formulation does not polymerize to the extent of the 50 and $10 \mathrm{wt} \%$ HDDA mixtures. Maximum reaction rates, dose at $R_{\mathrm{p}(\max )}$ final conversions at $R_{\mathrm{p}(\max )}$ are also listed in Table II for these ceramic mixtures.

The exotherm data and conversion plot for suspensions with various photoinitiator concentrations is shown in Figs 8 and 9, respectively. Selected polymerization data are listed in Table II for these mixtures as well. 


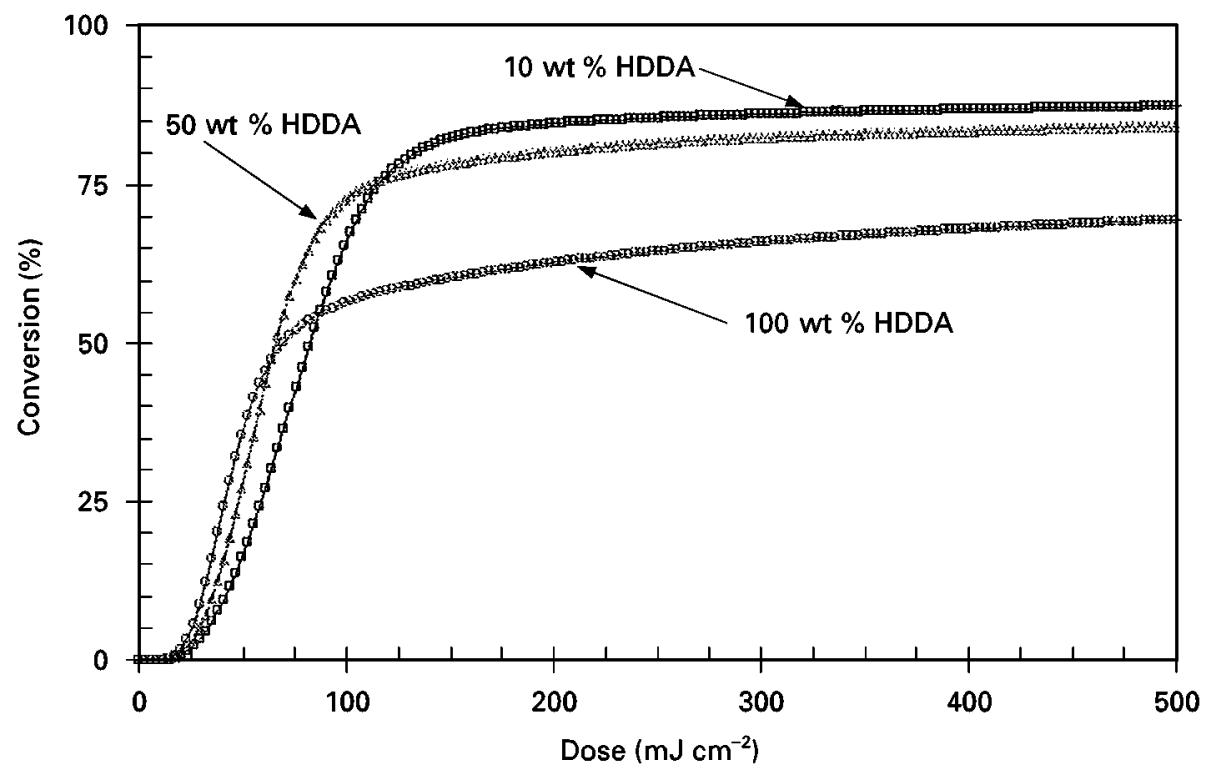

Figure 5 Conversion versus dose for next monomer mixtures.

TABLE II Polymerization data from DPC for all resins

\begin{tabular}{lrlll}
\hline Resin & $\begin{array}{c}\text { Max } R_{\mathrm{p}} \\
\left(\% \mathrm{~s}^{-1}\right)\end{array}$ & $\begin{array}{l}\text { Dose at } \\
\text { max. } \mathrm{R}_{\mathrm{p}} \\
\left(\mathrm{mJ} \mathrm{cm}^{-2}\right)\end{array}$ & $\begin{array}{l}\text { Conversion } \\
\text { at max. } \\
R_{\mathrm{p}}(\%)\end{array}$ & $\begin{array}{l}\text { Conversion } \\
\text { at 500 mJ } \\
\mathrm{cm}^{-2}(\%)\end{array}$ \\
\hline Neat 100 & \multicolumn{1}{c}{10.4} & 39 & 22.3 & 69.4 \\
Neat 50 & $10.6 \pm 0.2$ & $56 \pm 0$ & $36.3 \pm 2.1$ & $86.1 \pm 4.1$ \\
Neat 10 & $8.1 \pm 0.1$ & $75 \pm 2$ & $42.0 \pm 1.2$ & $87.2 \pm 0.4$ \\
Filled 100 & $7.8 \pm 1.0$ & $43 \pm 2$ & $19.7 \pm 1.7$ & $72.7 \pm 1.7$ \\
Filled 50 & $13.0 \pm 1.2$ & $44 \pm 3$ & $31.9 \pm 0.5$ & $88.3 \pm 2.3$ \\
Filled 10 & $8.9 \pm 1.2$ & $58 \pm 3$ & $32.9 \pm 3.0$ & $90.3 \pm 2.1$ \\
Filled 100-1.0 & $10.3 \pm 2.4$ & $37 \pm 2$ & $22.3 \pm 2.6$ & $75.3 \pm 4.3$ \\
Filled 100-2.0 & $10.4 \pm 3.0$ & $39 \pm 7$ & $22.7 \pm 2.2$ & $77.2 \pm 4.3$ \\
Filled 100-3.0 & $13.3 \pm 2.3$ & $32 \pm 2$ & $26.5 \pm 3.0$ & $78.9 \pm 3.1$ \\
\hline
\end{tabular}

\section{Discussion}

\subsection{Photopolymerization of bulk monomer mixtures}

The acrylate monomers studied here react via freeradical polymerization initiated by UV radiation. Free-radical polymerization occurs via the following initiation, propagation and termination reactions initiation

$$
R^{\prime}+M \rightarrow R M^{\prime}
$$

propagation

$$
R M_{i}^{\prime}+M \rightarrow R M_{i+1}^{\prime \prime}
$$

termination

$$
\begin{gathered}
R M_{i}^{\prime}+R M_{j}^{\prime} \rightarrow R M_{i+j} R \text { (combination) } \\
R M_{i}^{\prime}+R M_{j}^{\prime} \rightarrow R M_{i}+R M_{j} \text { (disproportionation) }
\end{gathered}
$$

where $R$ is the free radical, and $M$ the monomer. Initiation is controlled by absorption of UV radiation by the photoinitiator, 1-hydroxy cyclohexyl phenyl ketone (HCPK). The rate of polymerization is gener- ally given by

$$
R_{\mathrm{p}}=\frac{k_{\mathrm{p}}}{k_{\mathrm{t}}^{1 / 2}}[M]\left[R_{i}^{1 / 2}\right]
$$

where $k_{\mathrm{p}}$ and $k_{\mathrm{t}}$ are rate constants for propagation and termination reactions, $[M]$ is monomer concentration and $R_{i}$ is the rate of initiation. The main factors which determine $R_{\mathrm{p}}$ of a given acrylate system are type and concentration of photoinitiator, intensity, and wavelength distribution output of the UV source.

Exotherm curves for each monomer mixture are shown in Fig. 4. In each case the polymerization rate rapidly increases to a maximum, decreases almost as quickly, then tails off to negligible levels. This sharp rise in the reaction rate indicates autoacceleration of the bulk polymerization reaction. Autoacceleration is due to both the fast reactivity of the monomers and the autocatalytic nature of the reaction. After reaching the polymerization rate maximum, $R_{\mathrm{p}(\max )}$, the reaction self-decelerates as the polymer gels. Then the polymerization rate decreases to a negligible level at about $200 \mathrm{~mJ} \mathrm{~cm}^{-2} \mathrm{UV}$ dose or about $30 \mathrm{~s}$ (at an intensity of $7.3 \mathrm{~mW} \mathrm{~cm}^{-2}$ ). This polymerization behaviour is quantitatively and qualitatively representative of similar acrylate systems [11-14] photopolymerized in bulk.

The polymerization rate varies significantly as the monomer conversion increases, as shown in Fig. 10. This is due to the complex kinetics of bulk polymerization of these fast-reacting multifunctional monomers. For each composition, the reaction rate increases rapidly during the early stages of monomer conversion (between $0 \%$ and 20\%). In this regime, the 100\% HDDA resin reacts more quickly than the 50\% HDDA which is faster than the $10 \%$ HDDA resin. The density of $\mathrm{C}=\mathrm{C}$ bonds is highest in the $100 \%$ HDDA composition and lowest in the 10\% HDDA resin, so it should be expected that the acceleration of the polymerization reaction is greatest for the $100 \%$ 


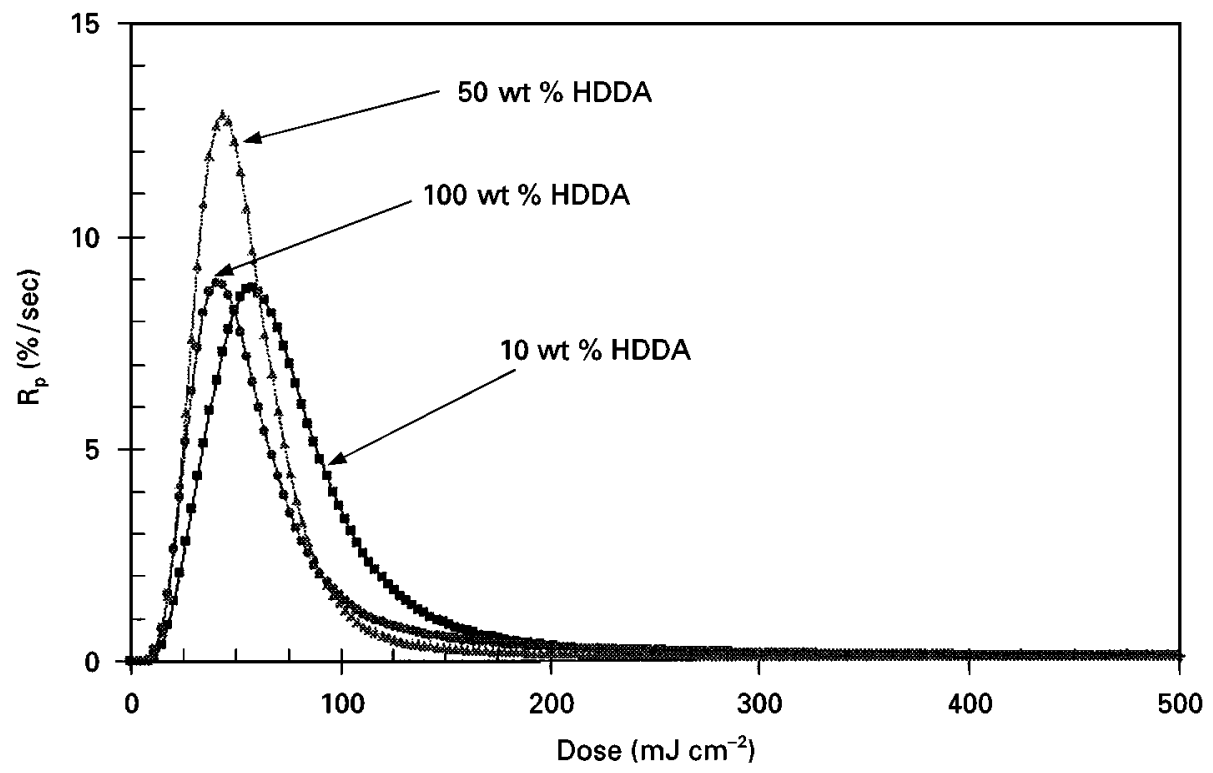

Figure 6 Rate of polymerization versus dose for monomer mixtures filled to $50 \mathrm{vol} \% \mathrm{Al}_{2} \mathrm{O}_{3}$.

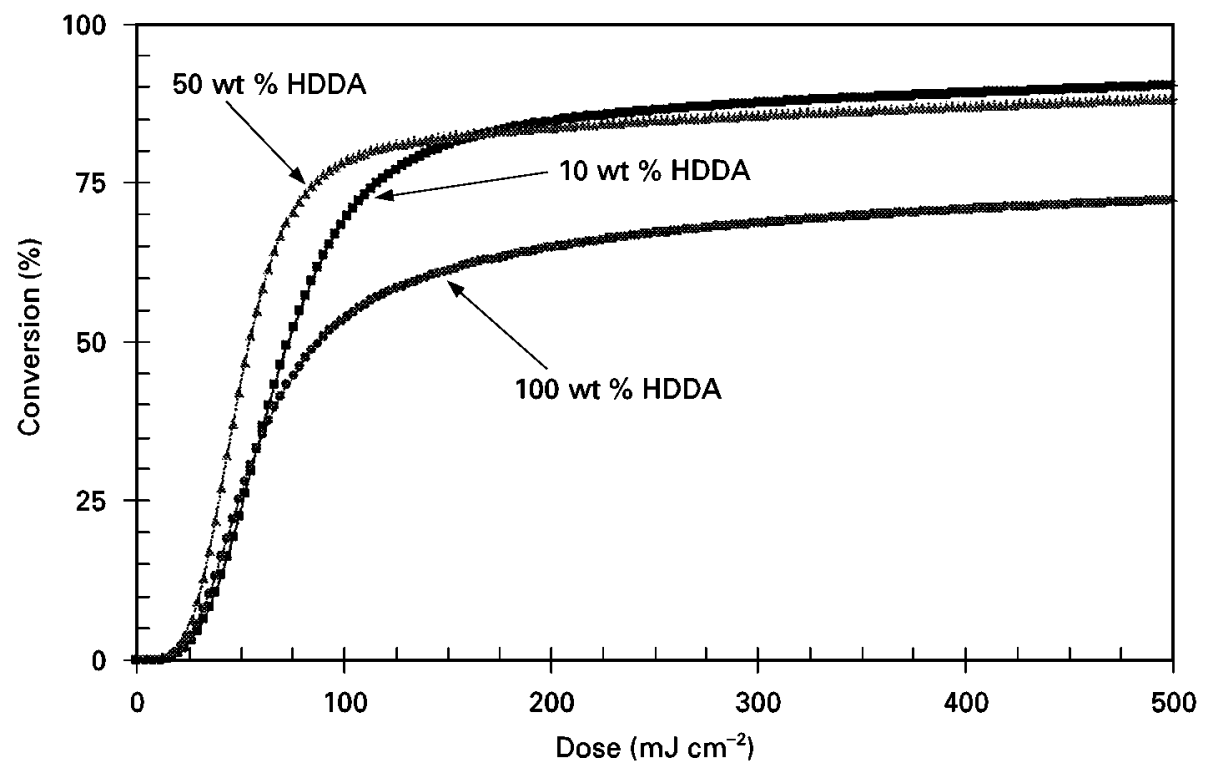

Figure 7 Conversion vesus dose for monomer mixture filled to $50 \mathrm{vol} \% \mathrm{Al}_{2} \mathrm{O}_{3}$.

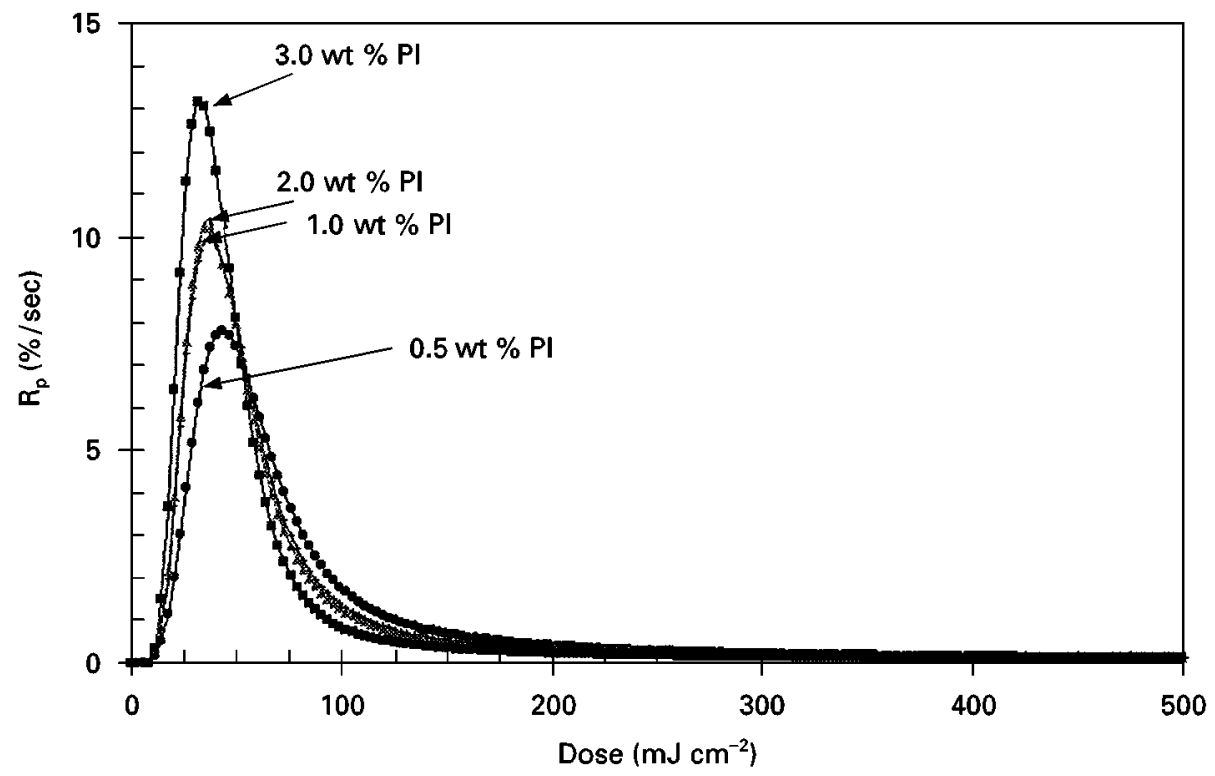

Figure 8 Rate of polymerization versus dose for $50 \mathrm{vol} \% \mathrm{Al}_{2} \mathrm{O}_{3}$ HDDA with various photoinitiator concentrations. 


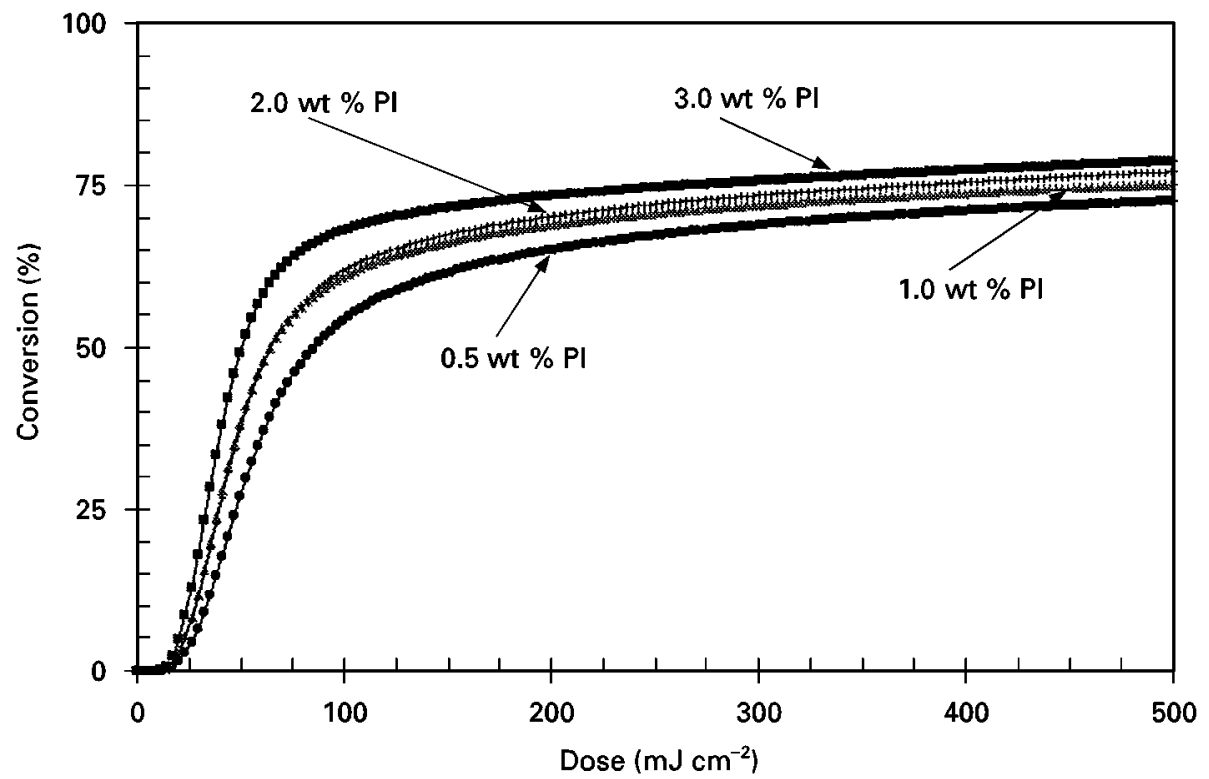

Figure 9 Conversion versus dose for $50 \mathrm{vol} \% \mathrm{Al}_{2} \mathrm{O}_{3}$ HDDA with various photoinitiator concentrations.

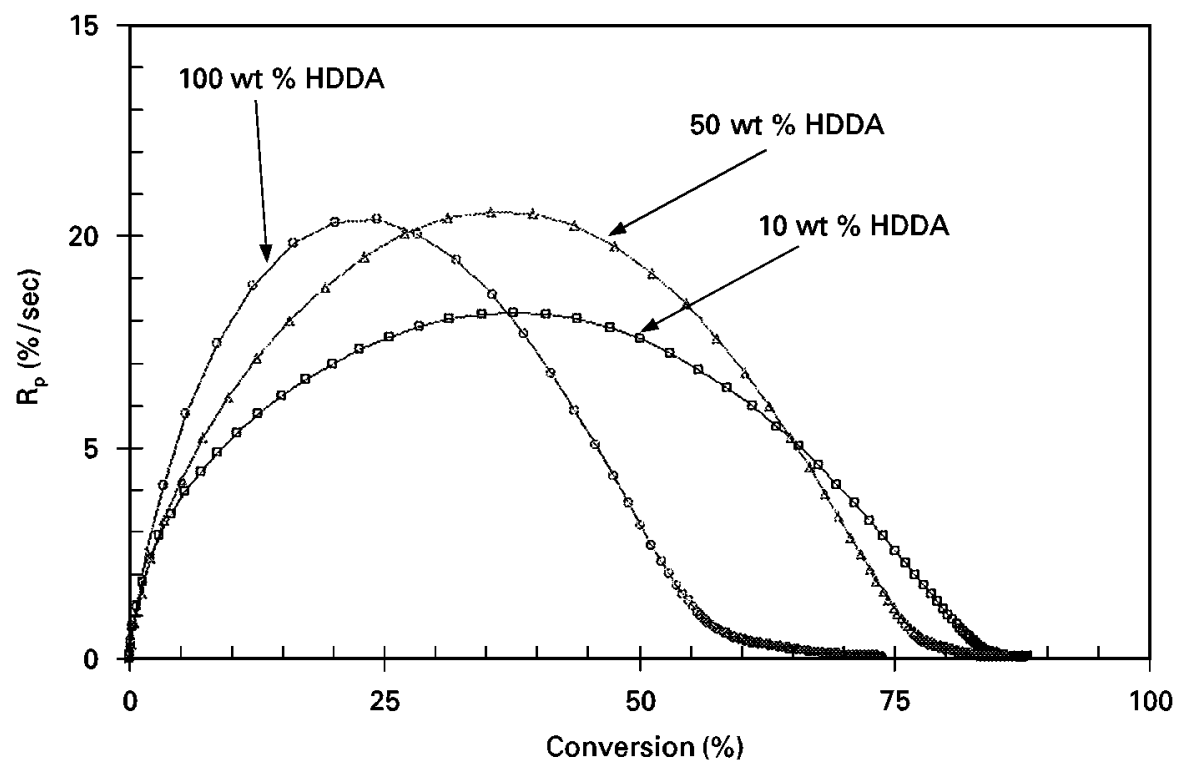

Figure 10 Rate of polymerization versus conversion for neat monomer mixtures.

HDDA resin followed by the $50 \%$ then $10 \%$ HDDA resins. However, at $22 \%$ conversion of the $100 \%$ HDDA resin, it has reached its maximum $R_{\mathrm{p}}$ while the other systems with lower HDDA contents still have increasing $R_{\mathrm{p}}$.

As the polymerization reaction proceeds, the maximum rate, $R_{\mathrm{p}(\max )}$, is reached at decreasing monomer conversions as the content of HDDA increases. This behaviour, illustrated in Fig. 11 is also seen in other mono-di- functional monomer copolymerizations [19]. Near the end of the reaction, where $R_{\mathrm{p}}$ is less than $2 \% \mathrm{~s} \mathrm{~s}^{-1}$, each composition polymerizes to increasing conversions as HDDA content decreases. A plot of the final conversion as a function of weight per cent HDDA is also shown in Fig. 11.

During polymerization, the probability of reaction is proportional to the degree of freedom of radicals. The higher the mobility of the reactive species, the faster it will react. When there are two reaction sites per monomer, as is the case for HDDA, the reaction of the first site "ties" the monomer to a growing polymer gel. The mobility restriction would then depend upon the size of the polymerized region to which it is tied. This behaviour necessarily leads to the development of an inhomogeneous, or microgel structure, which has been confirmed theoretically and experimentally $[19,20]$. Further discussion of the development of the gel structure is beyond the scope of this paper.

It can be noted from Fig. 11 that as the amount of difunctional monomer is increased, the final amount of monomer conversion decreases. A greater degree of cross-linking occurs in the monomer mixtures with higher difunctional content. These mixtures would tend to trap more radicals and occlude more unreacted monomer during polymerization than mixtures with lower difunctional monomer content. HDDA and other difunctional monomers polymerized in the 


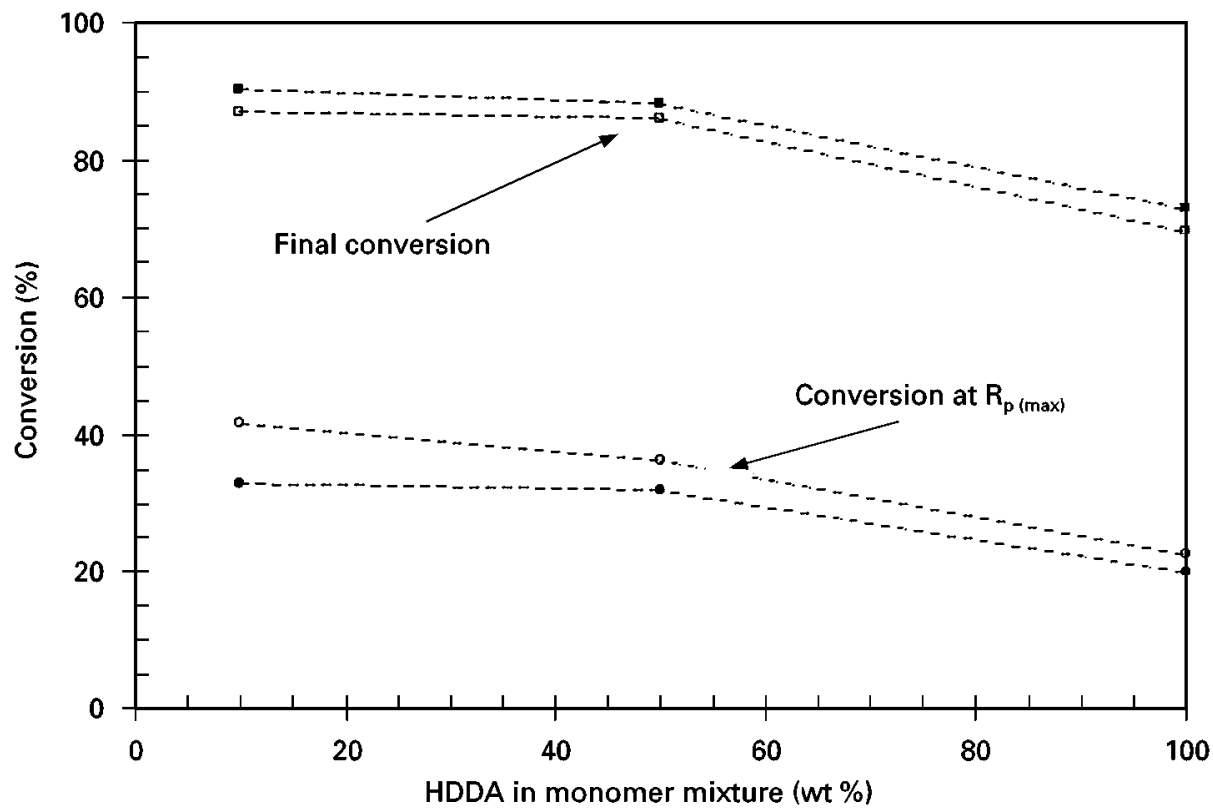

Figure 11 Comparison monomer conversion for neat and ceramic-filled resin according to monomer composition. $(O$, maximum $R_{\mathrm{p}}:(\square, \mathbf{\square})$ final conversion, neat resin; filled symbols: ceramic-filled resin.

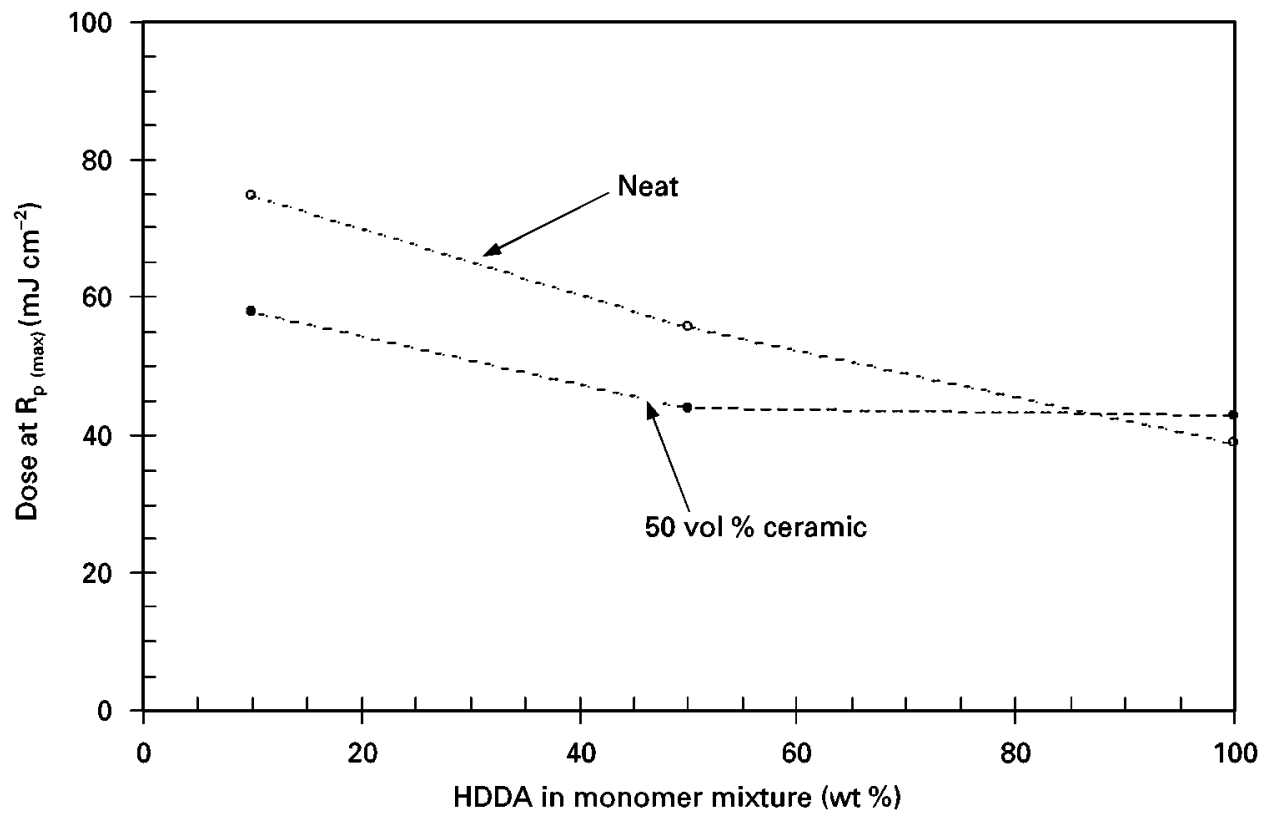

Figure 12 Comparison of dose at maximum polymerization rate for unfilled and ceramic-filled resins. neat resin; ceramic-filled resin.

bulk are known to contain trapped, unreacted monomers within the polymer gel [13].

The severe mobility restrictions imposed during cross-linking tend to change propagation and termination reactions mechanisms to diffusion control $[13,14,21]$. Also, in mixtures with higher concentrations of difunctional monomer (HDDA), the point at which the system gels will shift to earlier times (lower doses). This is illustrated in Fig. 12.

\subsection{Photopolymerization of ceramic suspensions}

The photopolymerization behaviour of the ceramic resins are surprisingly similar to the neat resins. The exotherm curves shown in Fig. 6 exhibit both autoacceleration and autodecceleration. The monomer conversion curves, Fig. 7, show similar behaviour as well. The dependence of $R_{\mathrm{p}}$ on the amount of monomer conversion, shown in Fig. 13 also exhibits qualitatively similar behaviour, increasing to a maximum, decreasing, and slowing to below $2 \%$ near the end of the reaction. The effects of monomer composition on the final conversion, as well as conversion at $R_{\mathrm{p}(\max )}$ are also qualitatively similar to the neat monomer mixtures as shown in Fig. 11.

The presence of the alumina particles does not appear to hinder the photopolymerization reaction at all. Unlike other common inorganic pigments like $\mathrm{TiO}_{2}$ (rutile, anatase), $\mathrm{ZnS}$, or carbon black which 


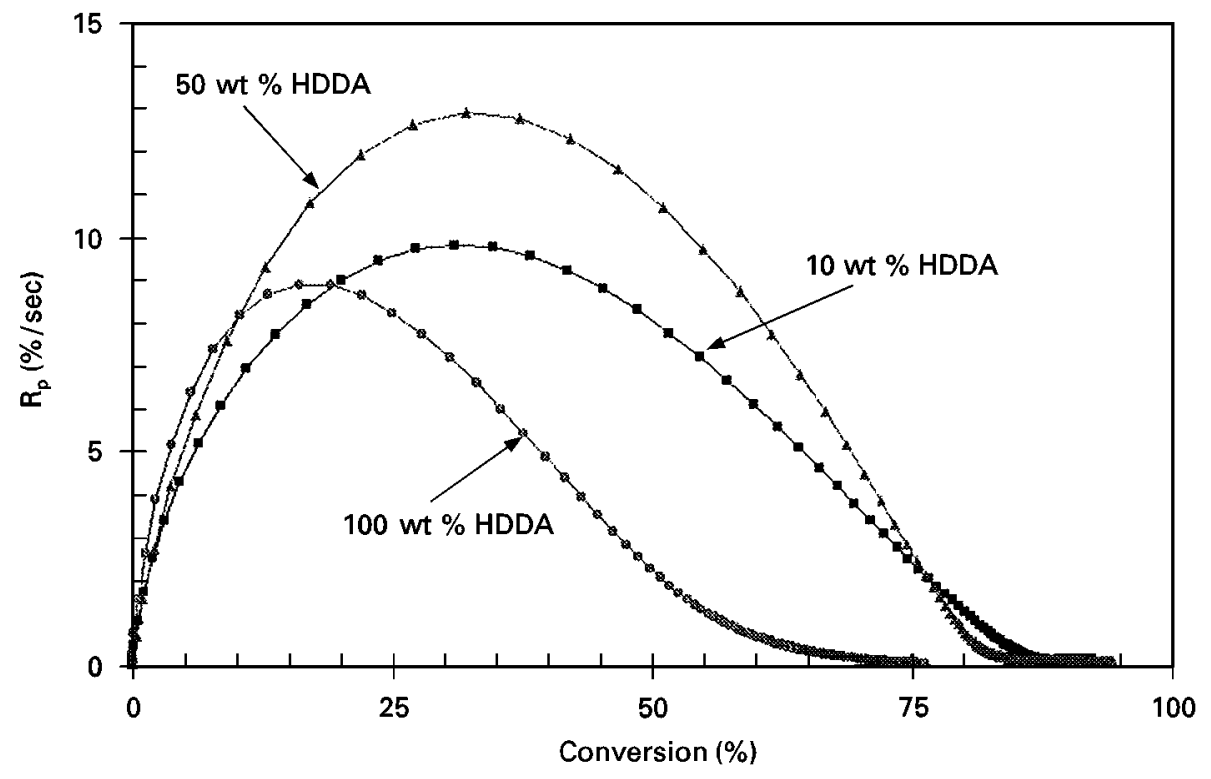

Figure 13 Rate of polymerization versus conversion for monomer mixtures filled to 50 vol $\% \mathrm{Al}_{2} \mathrm{O}_{3}$.

absorb UV radiation [15], alumina is transparent to light in the UV range [22]. The alumina particles serve only as scattering centres for the UV radiation. The difference in index of refraction between the suspended alumina particles and the surrounding liquid monomer mixture causes scattering of the UV photons. The degree of scattering is controlled by $1 / \Delta n^{2}$, where $\Delta n$ is the difference in indices of refraction [16]. The path of a photon becomes convoluted as it scatters from particle surface to particle surface. In effect, the path length of a photon is much longer in the ceramic suspensions than in the clear mixtures. So, the photon has many chances for absorption in the monomer liquid between scattering events. Because there is no significant competition between the photoinitiators and the alumina particles for the UV radiation, the presence of the ceramic particles has no deleterious affect upon photointiation or subsequent polymerization.

There appears to be a slight difference in the dependence of the polymerization rate on conversion for the filled resins as compared to the neat resins. Comparison between the ceramic-filled and neat monomer mixtures is shown in Fig. 11 for each monomer composition. The ceramic-filled mixtures have slightly lower monomer conversions at $R_{\mathrm{p}(\max )}$ than the unfilled mixture of the same composition. Yet, the filled resins have a slightly higher final conversion compared to the unfilled resins. Normally, if $R_{\mathrm{p}(\max )}$ is reached at lower monomer conversions, this would indicate earlier gelation and the subsequent final conversion would be lower as a result. Assuming that $R_{\mathrm{p}(\max )}$ is an indication, or rather is a result of gelation, this behaviour suggests that as the polymer network forms, the presence of the ceramic particles may induce colloidal gelation, rather than polymeric gelation, at an earlier stage (at lower conversion) than in neat monomer mixtures. If the final conversions were lower than the neat mixtures, then the cause would be attributed to the cross-linking and subsequent mobil- ity restrictions. However, because this is not the case, this might imply mobility restrictions arising from colloidal gelation of the suspension.

\subsection{Effect of photoinitiator concentration}

The overall shape of the polymerization exotherms are very similar for the filled resins containing various photoinitiator concentration. Clearly, increasing the photoinitiator concentration increases the maximum rate of polymerization as shown in Fig. 8. This result is most likely due to the increase in initiation rate. Also, as shown in Fig. 9, the final monomer conversion increases with photoinitiator concentration. This suggests that a greater number of initiation sites eventually leads to a more fully polymerized system. This is clearly shown in Fig. 14 and 15. The rate of polymerization of the ceramic resins with higher concentrations of photoinitiator are consistently higher at all monomer conversions. Apparently, the amount of photoinitiator of up to $3 \mathrm{wt} \%$ does not adversely affect the rate of polymerization through competitive side reactions such as initiator recombination and chain transfer to initiator.

\subsection{Effect of oxygen}

It is known [13] that the presence of oxygen inhibits the polymerization of acrylates. The DPC experiments carried out in this work were performed in nitrogen, eliminating the effect of oxygen inhibition. When these samples are irradiated in air, the polymerization is inhibited to a significant degree. Shown in Fig. 16 is a plot of polymerization rate versus monomer conversion which compares two samples cured in air and two in nitrogen. The air-cured samples have significantly lower polymerization rates and very low conversions. They also exhibit an induction period of about $50 \mathrm{~s}$, compared to about $1 \mathrm{~s}$ for the samples cured in nitrogen. At a photoinitiator concentration of $0.5 \mathrm{wt} \%$, 


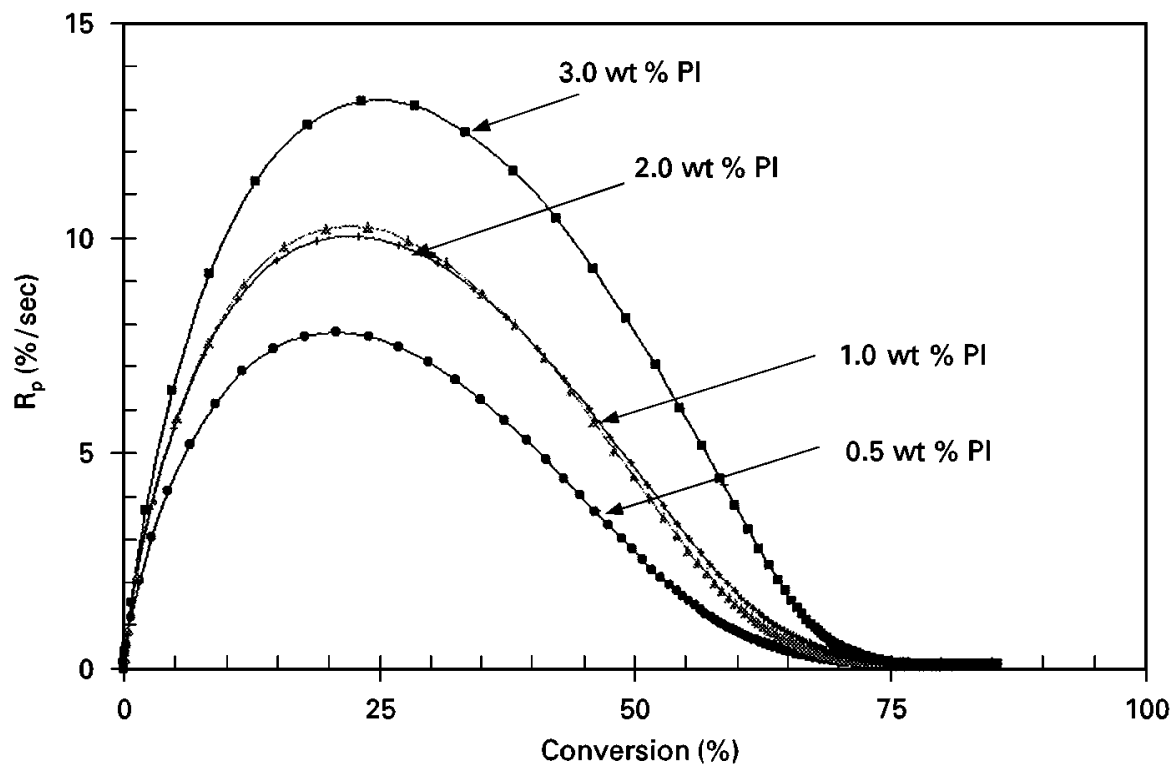

Figure 14 Rate of polymerization versus conversion for $50 \mathrm{vol} \% \mathrm{Al}_{2} \mathrm{O}_{3}$ HDDA with various photoinitiator concentrations.

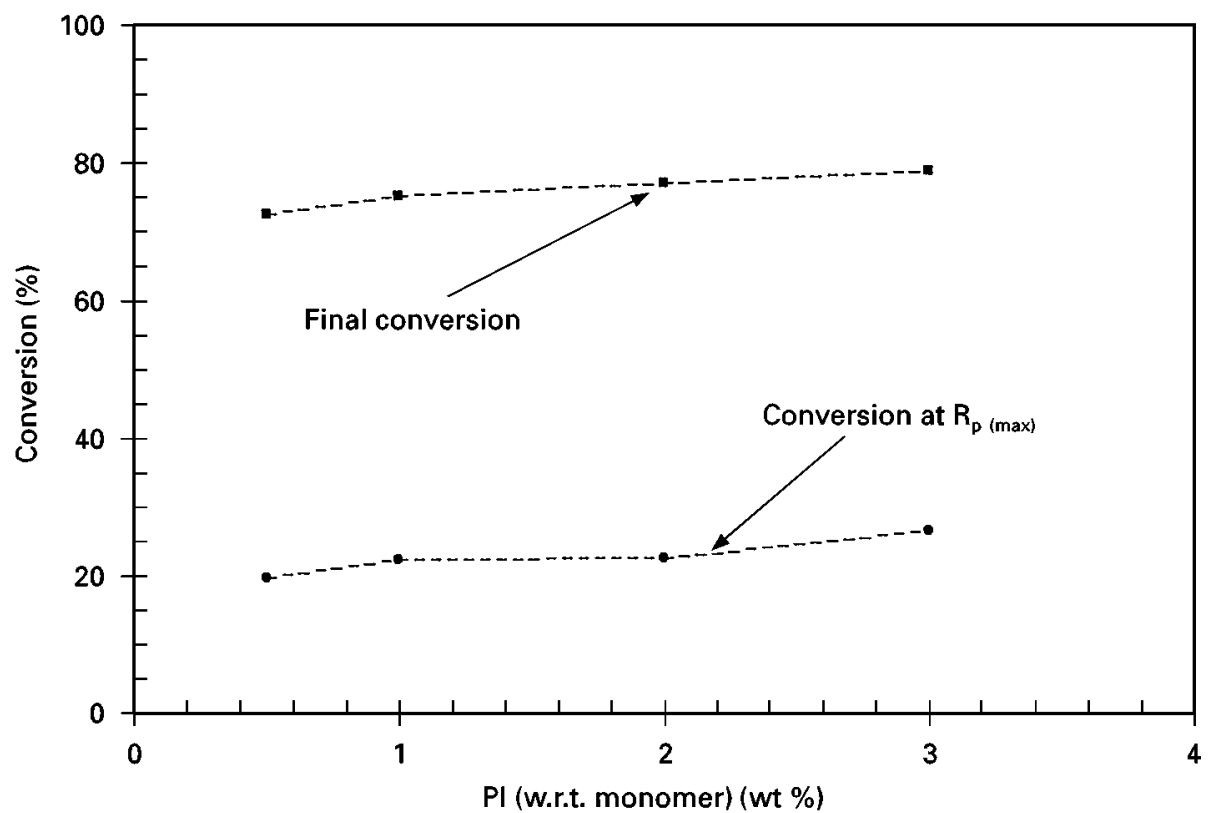

Figure 15 Comparison of monomer conversions for $50 \mathrm{vol} \% \mathrm{Al}_{2} \mathrm{O}_{3}$ HDDA resin according to photoinitiator concentration. conversion at maximum $R_{\mathrm{p}}$ : final conversion.

polymerization in air is almost completely suppressed. At $3.0 \mathrm{wt} \%$ photoinitiator concentration, the polymerization rate is detectable, but the peak rate reaches just $0.6 \% \mathrm{~s}^{-1}$. The final conversion reaches only $13 \%$. During free-radical polymerization in air, the initiation and propagation steps have to compete with oxygen-quenching reactions

initiation quench

$$
\mathrm{PI}^{\prime}+\mathrm{O}_{2} \rightarrow \mathrm{PI}+\mathrm{O}_{2}^{\prime}
$$

Propagation quench

$$
\mathrm{RM}_{i}^{\prime}+\mathrm{O}_{2} \rightarrow \mathrm{RM}_{i} \mathrm{OO}^{\prime}
$$

Propagation quench

$$
\mathrm{RM}_{i} \mathrm{OO}^{\prime}+\mathrm{RH} \rightarrow \mathrm{RM}_{i} \mathrm{OOH}+R
$$

where PI is photoinitiator. Molecular oxygen quenches the active initiators, reducing the rate of initiation. Oxygen also quenches active polymer segments during polymerization leaving a peroxy radical which is ineffective in initiating polymerization with acrylates, reducing the rate of polymerization [23]. An increased induction period, severely reduced rates of polymerizations and very low conversion rates, are the result of oxygen inhibition in these systems.

\section{Conclusions}

Fine alumina suspensions were prepared in UV curable suspensions. These colloidal dispersions are stable for long periods of time and have a viscosity of about $200 \mathrm{mPas}$ at $50 \mathrm{vol} \%$ loading of alumina. The 


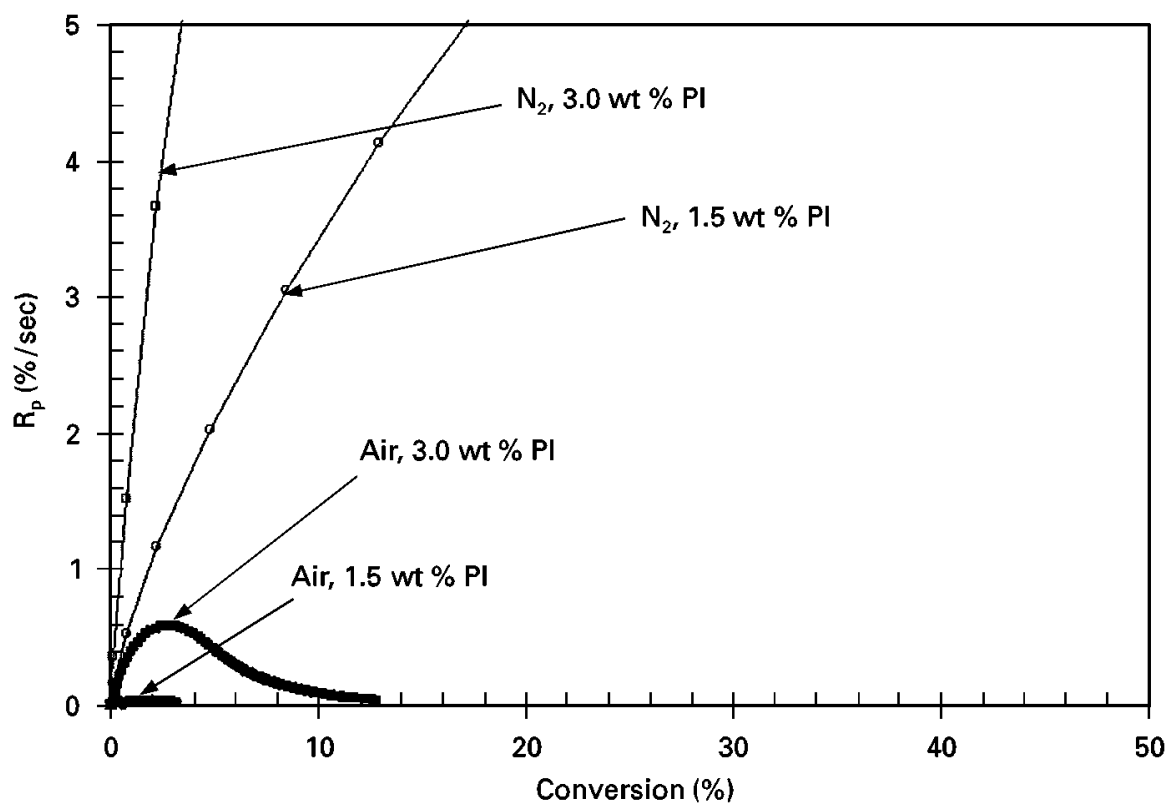

Figure 16 Comparison of polymerization rate versus monomer conversion for 50 vol $\% \mathrm{Al}_{2} \mathrm{O}_{3} / \mathrm{HDDA}$ with 0.5 and 3.0 wt $\%$ photoinitiator in both air and nitrogen.

resins with the highest concentrations of HDDA had the lowest conversion levels compared to resins with mixtures of single and di-functional monomers. The ceramic-filled resins photopolymerized at rates comparable to resins without ceramic particles and reached slightly higher levels of conversion. The presence of the ceramic particles did not appear to affect the photopolymerization process in any significant way. Increasing the amount of photoinitiator in the ceramic resins served to increase both the maximum rate of polymerization as well as the final level of conversion. Oxygen inhibition was shown significantly to suppress the rate of polymerization and conversion of the ceramic suspensions when irradiated in air.

\section{Acknowledgement}

The authors thank Steve Fishman, Office of Naval Research, for support of this research under contract N00014-95-1-0527.

\section{References}

1. R. Mistler, Am. Ceram. Soc. Bull. 69 (1990) 1022.

2. DEBORAH J. SMITH, ROBERT E. NEWNHAM and SHOKO YOSHIKAWA, in "IEEE 7th International Symposium on Applications of Ferroelectrics", (Cat. No. 90CH28001) (IEEE, New York, 1991) p. 426.

3. T. CHARTIER, R. PENARROYA, C. PAGNOUX and J. F. BAUMARD, J. Eur. Ceram. Soc. 17 (1997) 765.

4. G. A. BRADY and J. W. HAlloran, J. Am. Ceram. Soc. (1997) submitted.

5. G. A. BRADY, J. W. HALLORAN and L. W. LIN, ibid. (1998) in press.

6. H. LiAO and T. COYLE, J. Can. Ceram. Soc. 65 (1996) 254.

7. G. A. BRADY and J. W. HALLORAN, Naval Research Reviews, (1998) in press.

8. M. L. GRIFFITH and J. W. HALLORAN, ibid. 79 (1996) 2601.
9. R. GARG, R. K. PRUD'HOMME and I. AKSAY, presented at the 99th Annual Meeting of the American Ceramic Society, Cincinnati, OH (1997).

10. S. VENTURA, et al., in "Proceedings of the Seventh International Conference on Rapid Prototyping”, (SME, Dearborn, MI, 1997) p. 271.

11. C. HOYLE, in "Radiation Curing: Science and Technology" edited by S. Peter Pappas (Plenum Press, NY, 1992) p. 61.

12. J. G. Kloosterboer, G. M. M. Van de Hei, R. G. GOSSINK and G. C. M. DORTANT, Polym. Commun. 25 (1984) 322.

13. E. SELLI and I. R. BELLOBONO, in "Radiation Curing in Polymer Science and Technology", edited by J. P. Fouassier and J. F. Rabek, Vol 3 (Elsevier, NY, 1993) p. 1.

14. K. S. ANSETH, C. N. BOWMAN and N. A. PEPPAS, J. Polym. Sci. 32 (1994) 139.

15. C. LOWE, in "Radiation Curing in Polymer Science and Technology", edited by J. P. Fouassier and J. F. Rabek, Vol 4 (Elsevier, NY, 1993) p. 92.

16. MiChelle L. GRifFith and J. W. HAllor An, J. Appl. Phys. 81 (1997) 2538.

17. G. AlLEN BRADY and J. W. HALlor AN, Rapid Prototyping J. 3 (1997) 61.

18. J. E. MOORE, in "UV Curing: Science and Technology", edited by J. E. Moore, Vol. 1 (Technology Marketing Corp., Stamford, CT, 1978) p. 133.

19. X. SUN, Y. Y. CHIU, L. J. LEE, Ind. Eng. Chem. Res. 36 (1997) 1343.

20. J. G. Kloosterboer, Adv. Polym. Sci. 84 (1988) 4.

21. K. S. ANSETH, C. M. WANG and C. N. BOWMAN, Macromolecules 27 (1994) 650.

22. L. BERGSTROM, A. MEURK, H. ARWIN and D. ROWCliffe, J. Am. Ceram. Soc. 79 (1996) 339.

23. C.-H. CHANG, A. MAR, A. TIEFENTHALER and D. WOSTRATZKY, in "Handbook of Coatings Additives", edited by L. J. Calbo, Vol. 2 (Marcel Dekker, New York, 1992) p. 1.

Received 4 December 1997 and accepted 15 May 1998 